\title{
Procedimentos analíticos em perícia ambiental/métodos químicos: técnicas de análise
}

Dentre as características do analista, está a atenção às questões relativas à exatidão e à precisão esperável dos métodos dados e, além disso, não deve desprezar fatores como tempo e custo. O método mais exato para certa determinação pode ser muito demorado ou envolver o uso de reagentes caros. Por tal motivo, o apropriado é avaliar que exatidão se faz necessária. Em muitos casos, é possível escolher um método que, embora menos exato, proporcione, num tempo razoável, resultados satisfatórios.

Palavras-chave: Perícia ambiental; Química analítica; Métodos químicos; Análises.

\section{Analytical procedures in environmental expertise/chemical methods: analysis techniques}

\begin{abstract}
Among the characteristics of the analyst is the attentiveness to the issues related to the accuracy and precision expected from the given methods and, beyond that, should not disregard factors such as time and cost. The most exact method for a given determination might be very time-consuming or involve expensive reagents. For this reason, the appropriate thing is to evaluate what accuracy is made necessary. In many cases, it is possible to choose e a method that, although less exact, provides, in a reasonable time, satisfactory results.
\end{abstract}

Keywords: Environmental expertise; Analytical chemistry; Chemical methods; Analysis.

Topic: Química Analítica

Reviewed anonymously in the process of blind peer.
Received: 07/12/2020

Approved: 20/03/2021
Gustavo Aveiro Lins

Universidade Federal Rural do Rio de Janeiro, Brasil

http://lattes.cnpq.br/5173989372426437

http://orcid.org/0000-0002-0244-6925

gustavoaveiro@gmail.com

\section{Evandro Lima (1)}

Universidade Federal Rural do Rio de Janeiro, Brasil

http://lattes.cnpq.br/7057930279111732

http://orcid.org/0000-0003-4213-9652

evandroabpga@gmail.com

Cleber Vinicius Vitorio da Silva (id

Universidade Federal Rural do Rio de Janeiro, Brasil

http://lattes.cnpq.br/4275890458575782

http://orcid.org/0000-0001-8337-9615

clebervitorio88@gmail.com

\author{
Raphael do Couto Pereira (iD \\ Escola Naval, Brasil \\ http://lattes.cnpq.br/2232319377341816 \\ http://orcid.org/0000-0002-3934-4332 \\ rcoutopereira1@gmail.com \\ Lais Alencar de Aguiar (iD \\ Comissão Nacional de Energia Nuclear, Brasil \\ http://lattes.cnpq.br/5785500333245448 \\ http://orcid.org/0000-0002-1551-4085 \\ aguiar.lais@gmail.com \\ Josimar Ribeiro de Almeida (iD \\ Universidade do Estado do Rio de Janeiro, Brasil \\ http://lattes.cnpq.br/3215586187698472 \\ http://orcid.org/0000-0001-5993-0665 \\ almeida@poli.ufri.br
}

Referencing this:

LINS, G. A.; LIMA, E.; SILVA, C. V. V.; PEREIRA, R. C.; AGUIAR, L. A.; ALMEIDA, J. R.. Procedimentos analíticos em perícia ambiental/métodos químicos: técnicas de análise. Engineering Sciences, v.9, n.1, p.1-12, 2021. DOI:

http://doi.org/10.6008/CBPC2318-3055.2021.001.0001 


\section{INTRODUÇÃO}

Dispondo-se de uma amostra apropriada, é necessário dedicar atenção à técnica, ou às técnicas, mais convenientes de serem empregadas para as determinações requeridas. Uma das decisões principais, a ser tomada pelo analista, é a da escolha do procedimento mais eficiente de uma dada análise; para chegar à decisão correta, o analista deve ter familiaridade com os detalhes práticos das diversas técnicas e com os princípios teóricos sobre os quais se baseiam: deve também ter o conhecimento das condições em que cada método é confiável e a consciência das interferências possíveis que podem ocorrer, e ser capaz de imaginar caminhos para evitar estes problemas (ALMEIDA et al., 2019). $O$ analista também terá atenção às questões relativas à exatidão e à precisão esperável dos métodos dados e, além disso, não deve desprezar fatores como tempo e custo. O método mais exato para certa determinação pode ser muito demorado ou envolver o uso de reagentes caros. Por tal motivo, o apropriado é avaliar que exatidão se faz necessária. Em muitos casos, é possível escolher um método que, embora menos exato, proporcione, num tempo razoável, resultados satisfatórios (ALMEIDA et al., 2019).

\section{RELATO}

Apesar das vantagens diversificadas dos métodos instrumentais, a sua generalizada adoção não tornou obsoletos os métodos clássicos; três fatores principais influenciam a situação: A aparelhagem necessária para os procedimentos clássicos é barata e encontra se com facilidade em todos os laboratórios; muitos instrumentos, no entanto são Instrumentação em Ciência Forense caros e a sua adoção só se justifica quando são muitas as amostras a analisar, ou quando se trata da determinação de substâncias em quantidades diminutas (análise de traços, subtrações ou ultratraços). Nos métodos instrumentais é necessário efetuar uma operação de calibração, em que se usa amostra do material com a composição conhecida como a substância de referência. Enquanto um método instrumental é o ideal para a execução de um grande número de determinações de rotina, no caso de uma análise episódica, fora da rotina, é muitas vezes mais simples usar um método clássico do que ter o trabalho de preparar os padrões indispensáveis e calibrar o instrumento.

\section{DISCUSSÃO}

Importante destacar que as pesquisas orientadas pelo método dialético revelam a historicidade do fenômeno e suas relações, em nível mais amplo, situam o problema dentro de um contexto complexo, ao mesmo tempo, estabelece e aponta as contradições possíveis dentre os fenômenos investigados. A investigação qualitativa é alicerçada na inseparabilidade dos fenômenos e seu contexto, pois, as opiniões, percepções e significados serão compreendidos com maior profundidade a partir da contextualização. A validade seria referente à semelhança entre o conceito e suas medidas, ao grau em que uma medida representa precisamente o que se espera. A garantia da validade começaria com a compreensão direta do que deve ser medido, sendo, portanto, uma questão de formulação da pesquisa. O método proposto foi 
dividido em três fases, as quais foram subdivididas em etapas para a realização do levantamento bibliográfico. Na primeira fase da pesquisa (Fase 1: Perguntas de pesquisa) verifica-se as principais decisões e definições acerca da pesquisa. As perguntas de pesquisa, ficam em destaque e servem como impulsos para o início da revisão. Define-se o tema para realizar o levantamento bibliográfico e o período disponível. Outras decisões são tomadas simultaneamente. Tais como a definição das palavras-chave, para atuarem como identificadores. Paralelamente, resumem os principais assuntos sobre o tema a se pesquisar; assim como as combinações das palavras-chave. Essas, por sua vez, podem ser feitas por meio da utilização dos operadores booleanos e em diferentes bases de dados tais como Portal de Periódicos CAPES, Base de dados SCIELO, Publish or Perish, EBSCO, entre outras. No presente caso, as bases de dados foram Web of Science (ou ISI), Plataforma SUSTENERE, Scielo e Scopus. Essas bases possuem fácil acesso, permitindo, por meio de suas ferramentas, uma pesquisa criteriosa seja realizada, abrangendo uma vasta quantidade de periódicos. A segunda fase (Seleção dos artigos) inicia o levantamento e a seleção dos artigos, utilizando-se dos critérios de exclusão. Utiliza-se das palavras-chave de exclusão para realizar classificação mais criteriosa dos artigos. Delimitando também o período. Na etapa seguinte ocorre o primeiro filtro dos artigos, faz-se uma seleção a partir dos títulos, identificando os não alinhados. Na próxima etapa se faz a leitura dos resumos para excluir os impertinentes ao tema pesquisado. A etapa seguinte contém uma análise subjetiva do pesquisador para identificar, nos artigos alinhados ao tema, aqueles que possuem maior relevância acadêmica. Uma análise bibliométrica indica a relevância do autor/artigo para a composição do referencial bibliográfico. A Fase 3 corresponde a Classificação dos artigos selecionados. Procede-se a organização das amostras de artigos selecionados. O objetivo é ordenar, um padrão que vai variar de acordo com a necessidade do pesquisador e a prioriza como foco para desenvolvimento temático. Evidencia-se a importância da análise minuciosa dos artigos que compõem a amostra. Em pesquisas qualitativas, a concepção de validade assume formas distintas, pois a discussão sobre escalas de medição não se aplica a métodos qualitativos, sendo necessária a compreensão da validade em outra perspectiva.

Um atributo que se relaciona com a objetividade, com a possibilidade de repetição do experimento, com o fato de a pesquisa estar aberta à verificação por outras pessoas e com a capacidade de generalização (ALMEIDA et al., 2013). A validade pode ser vista genericamente como a correspondência entre a pesquisa e a realidade. Ela se refere à verificação dos resultados como verdadeiros e confiáveis. Ela estaria relacionada ao fato de os resultados refletirem com precisão a situação analisada e serem confiáveis, no sentido de que não haveria razões para deles duvidar; ou seja, a pesquisa é válida se as evidências fornecem o apoio necessário às suas conclusões (SOUZA et al., 2011). A intenção não é generalizar, mas sim descrever, analisar, buscar compreender.

\section{CONSIDERAÇÕES FINAIS}

Suponhamos que se solicite a um químico analítico, planejar um procedimento para a determinação quantitativa da substância X. Aqui vai uma lista das perguntas que se deve formular antes de empreender a incumbência: Que intervalo de valores se pode esperar? Qual é a matriz ou o material em maior quantidade, 
onde se encontra a substância procurada? Que impurezas estão presentes e, aproximadamente, em que concentração? Que grau de precisão é exigido? Que grau de exatidão é exigido? Quais padrões de referências estão disponíveis? A análise deve ser feita no laboratório, no local de fabricação ou no campo? Que fontes de energia e outras facilidades se podem usar? Espera-se analisar quantas amostras por dia? É essencial obter uma resposta rápida? Se for, com que rapidez? Em que forma física se deseja a resposta (registro automático, fita impressa ou perfurada, relatório escrito, telefônico, etc.)? Se for necessário treinamento especial do pessoal, pode-se consegui-lo? Pode acontecer que seja necessário um compromisso; por exemplo, alta precisão não é compatível com velocidade. Em vários casos, a preferência pessoal pode ser um fator decisivo. Assim, pode-se fazer com que os métodos colorimétricos e polarográficos forneçam quase a mesma exatidão com amostras de diluição semelhante; o tempo consumido nos dois procedimentos é comparável e mesmo o custo do aparelho é mais ou menos o mesmo. $\mathrm{O}$ analista tem, pois, liberdade de escolha do método que Ihe seja mais familiar. Muitos métodos de análises, geralmente aplicáveis, são destinados a auxiliar na escolha de um procedimento para vários tipos de amostras.

As técnicas têm diferentes graus de complicação, de sensibilidade, de seletividade, de custo e também de tempo, e é importante tarefa do analista a escolha do melhor procedimento para efetivar uma certa determinação. Para isto, será necessária a cuidadosa consideração dos seguintes critérios: (a) 0 tipo de análise que se quer - elementar ou molecular, rotineira ou episódica; (b) Os problemas decorrentes da natureza do material investigado, por exemplo; substâncias radioativas, substâncias corrosivas, substâncias afetadas pela água; (c) A possível interferência de componentes do material diferentes daqueles que têm interesse; (d) O domínio de concentração que precisa ser investigado; (e) A exatidão exigida; (f) As facilidades disponíveis; este critério refere-se particularmente ao tipo de equipamento à mão; (g) O tempo necessário para completar a análise; este critério será especialmente relevante quando se precisa com rapidez de resultados analíticos a fim de controlar um processo de fabricação. $\mathrm{O}$ que pode significar ser a exatidão uma consideração de caráter secundário e não primário, ou então que talvez seja preciso o uso de instrumentação cara; (h) O número de análises de mesmo tipo que devem ser efetuadas; em outras palavras, o analista fará um número limitado de determinações ou a situação exigirá análises frequentes e repetitivas; (i) A natureza da amostra. A espécie de informação que se procura, ou a grandeza da amostra disponível sugerem a adoção de métodos de análise não destrutivos, em contraposição aos métodos destrutivos mais comumente adotados que envolvem a dissolução da amostra (possivelmente num ácido) antes da aplicação das técnicas analíticas normais.

Qualquer que seja o método que se escolha para uma dada determinação, ele deve ser, no caso ideal, um método específico, isto é, capaz de medir com exatidão a quantidade de substância analisada, quaisquer que sejam as outras substâncias que possam estar presentes. Na prática, poucos procedimentos analíticos atingem este ideal, mas muitos métodos são seletivos, ou seja, podem ser usados para determinar qualquer íon de um pequeno grupo na presença de certos íons especificados. Em muitas circunstâncias consegue-se a seletividade desejada mediante a execução do procedimento em condições cuidadosamente controladas, especialmente no que se refere ao pH da solução. 
Tabela 1: Aplicabilidade comparativa de vários procedimentos analíticos.

\begin{tabular}{|c|c|c|}
\hline TIPO DE AMOSTRA & PROCEDIMENTO & APLICAÇÃO \\
\hline 1. Ligas, minérios & $\begin{array}{l}\text { a. Espectrografia Geral } \\
\text { b. Eletrodeposição Geral } \\
\text { c. Colorimetria } \\
\text { d. Ativação Específica } \\
\text { e. Absorção de raios-X } \\
\text { f. Fluorescência por raios-X }\end{array}$ & $\begin{array}{l}\text { Rápida } \\
\text { Mais lenta; aparelhos baratos } \\
\text { Mais específica, especialmente para } \\
\text { constituintes menores } \\
\text { Menos conveniente; Casos especiais. } \\
\text { Quando o elemento procurado e as } \\
\text { impurezas variam muito em massa atômica } \\
\text { Geral; rápida }\end{array}$ \\
\hline $\begin{array}{l}\text { 2. Traços de íons } \\
\text { metálicos }\end{array}$ & $\begin{array}{l}\text { a. Colorimetria } \\
\text { b. Nefelometria } \\
\text { c. Fluorimetria } \\
\text { d. Polarografia } \\
\text { e. Análises de desgaste }\end{array}$ & $\begin{array}{l}\text { São de sensibilidade e precisão } \\
\text { comparáveis; altamente específicos } \\
\text { Específicas e altamente sensíveis }\end{array}$ \\
\hline $\begin{array}{l}\text { 3. Misturas } \\
\text { gasosas }\end{array}$ & $\begin{array}{l}\text { a. Cromatografia gasosa } \\
\text { b. Gravimétrica } \\
\text { c. Volumétrica Misturas } \\
\text { d. Manométricos } \\
\text { e. Absorção no infravermelho } \\
\text { f. Espectro de massa }\end{array}$ & $\begin{array}{l}\text { Geral; alguma especificidade } \\
\text { Para dióxido de carbono ou água } \\
\text { Para determinar vários constituintes } \\
\text { Libertação ou absorção; amostra pequenas } \\
\text { Ensaios de rotina para um único componente } \\
\text { Geral; aparelho caro }\end{array}$ \\
\hline $\begin{array}{l}\text { 4. Misturas } \\
\text { (Não é necessária } \\
\text { separação completa) }\end{array}$ & $\begin{array}{l}\text { a. Espectro infravermelho } \\
\text { b. Espectro Raman } \\
\text { c. Difração de raios-X } \\
\text { d. Diluição isotópica } \\
\text { e. Espectro de massa } \\
\text { f. RMN }\end{array}$ & $\begin{array}{l}\text { Para compostos inorgânicos } \\
\text { Para compostos inorgânicos } \\
\text { Sólidos cristalinos } \\
\text { Análise para um único componente } \\
\text { Para compostos voláteis simples } \\
\text { Para líquidos }\end{array}$ \\
\hline 5. Misturas & a. Troca iônica & Para substâncias iônicas \\
\hline \multirow[t]{2}{*}{$\begin{array}{l}\text { (Procedimentos } \\
\text { de separação) }\end{array}$} & $\begin{array}{l}\text { b. Distribuição em contracorrente } \\
\text { c. Cromatografia de } \\
\text { partição } \\
\text { d. Cromatografia de } \\
\text { adsorção }\end{array}$ & $\begin{array}{l}\text { Devem ser parcialmente } \\
\text { solúveis em cada um dos } \\
\text { dois líquidos imiscíveis }\end{array}$ \\
\hline & e. Eletrodeposição & Para cátions metálicos \\
\hline
\end{tabular}

Frequentemente, no entanto, existem substâncias que, estando presentes, impedem a medição direta da quantidade de certo íon; estas substâncias são conhecidas como interferentes, e a escolha dos métodos de separação das interferências de uma substância a ser determinada é tão importante quanto a escolha do método de determinação.

Os procedimentos de separação típicos são: (a) Precipitação seletiva. A adição dos reagentes apropriados pode converter os íons interferentes em precipitados que podem ser filtrados: além disso, pode ser necessário cuidadoso controle do pH a fim de se conseguir uma separação nítida. Deve-se ter presente que os precipitados tendem a adsorver substâncias da solução e é preciso ter o cuidado para que a perda, através deste mecanismo, da substância a ser determinada seja tão pequena quanto possível; (b) Mascaramento. Junta-se à solução um agente complexante e se os complexos formados forem suficientemente estáveis não haverá reação com os reagentes adicionados na operação subsequente; isto pode ocorrer num procedimento titrimétrico ou num método de precipitação gravimétrica; (c) Oxidação seletiva (redução seletiva). A amostra é tratada por um agente oxidante, ou redutor, seletivo que reagirá com alguns dos íons presentes - a modificação provocada no estado de oxidação facilitará, muitas vezes, a separação. Por exemplo, para precipitar o ferro como hidróxido, a solução é sempre oxidada de modo que se precipite o hidróxido de ferro; este hidróxido precipita num pH mais baixo que o hidróxido de ferro, que pode 
ser contaminado pelos hidróxidos de muitos metais bivalentes; (d) Extração por solvente. Quando os íons metálicos são convertidos em compostos quelados, mediante o tratamento com reagentes orgânicos apropriados, os complexos resultantes são solúveis em solventes orgânicos e podem assim ser extraídos das soluções aquosas. Muitos complexos de associação iônica, que contêm íons volumosos de caráter principalmente orgânico (por exemplo, o íon tetrafenilarsônio ( $66 \mathrm{H} 5) 4 \mathrm{As}+$ ), são solúveis em solventes orgânicos e podem ser utilizados para extrair, da solução aquosa, os íons metálicos apropriados. Este tratamento pode ser usado para isolar o íon a ser determinado ou, então, para remover as substâncias interferentes; (e) Troca iônica. Os materiais de troca iônica são substâncias insolúveis que contêm íons capazes de substituição pelos íons de uma solução que contém eletrólitos. Em muitas análises que envolvem a determinação de metais, o íon fosfato é um interferente; em soluções que não sejam ácidas, os fosfatos da maioria dos metais são precipitados. No entanto, se a solução percolar uma coluna de resina trocadora aniônica, na forma cloreto, os íons fosfato serão substituídos por íons cloreto. Analogamente, a determinação dos fosfatos é difícil na presença de diversos íons metálicos; se a solução passar por uma coluna de resina trocadora catiônica, na forma protonada, os cátions interferentes serão substituídos por íons hidrogênio; (f) Cromatografia. O termo cromatografia aplica-se a técnica de separação em que os componentes de uma amostra (fase móvel) atravessam uma coluna com diferentes velocidades. A coluna, que constitui a fase estacionária do sistema, está preenchida por um sólido apropriado que varia de acordo com as propriedades químicas da amostra; usam-se para este fim diversos materiais como o pó de celulose, a sílica gel e a alumina. Introduzindo-se a solução de ensaio no topo da coluna, provoca-se o escoamento lento de um solvente apropriado (a fase móvel) coluna abaixo.

$\mathrm{Na}$ cromatografia de adsorção os solutos são adsorvidos pelo material do recheio da coluna e depois são eluídos pela fase móvel; os componentes que forem adsorvidos com maior dificuldade são eluídos em primeiro lugar e os componentes mais facilmente adsorvidos são eluídos mais lentamente, efetivando-se assim a separação. Na cromatografia de partição, os solutos repartem-se entre a fase móvel e uma película líquida (comumente de água) firmemente absorvida na superfície da fase estacionária. Um exemplo típico é o da separação entre o cobalto e o níquel numa solução concentrada de ácido clorídrico; a fase estacionária é a celulose em pó, a fase móvel é a acetona com ácido clorídrico. O cobalto é eluído enquanto o níquel permanece na coluna. Se forem escolhidos compostos com volatilidade adequada, pode-se efetuar uma cromatografia em fase gasosa na qual a fase móvel é uma corrente de gás, como o nitrogênio, por exemplo. No caso de líquidos é possível, muitas vezes, dispensar a coluna e usar o adsorvente espalhado numa camada fina sobre uma placa de vidro (cromatografia em camada fina), e em alguns casos pode ser usada uma folha de papel de filtro sem qualquer adição de adsorvente (cromatografia em papel). Estas técnicas são especialmente úteis para operar pequenas quantidades de material. São de particular interesse, no campo da cromatografia, os desenvolvimentos associados com a cromatografia líquida de alta eficiência (CLAE) e com a cromatografia iônica.

Uma vez escolhido o melhor método de tratar com as interferências, e escolhido o método de determinação mais apropriado, a análise deve ser realizada em duplicata ou preferivelmente em triplicata. 
No caso de determinações clássicas simples, os resultados experimentais devem ser anotados num registro de análise. No entanto, de modo geral, os equipamentos, nos métodos instrumentais de análise, são acoplados a computadores e os resultados analíticos podem ser expostos numa unidade visual, enquanto uma impressora proporciona o registro dos dados pertinentes que pode ser usado como documento permanente. Um cálculo simples converterá, então, os dados experimentais na informação que se procura; usualmente esta é a percentagem do componente relevante presente na amostra analítica. Os resultados que se obtêm terão um certo grau de incerteza, como qualquer outra medida física, e é preciso estabelecer a extensão desta incerteza a fim de se apresentarem resultados significativos da análise. Por isso é necessário estabelecer a precisão dos resultados, o que significa o grau da reprodução dos valores. Exprime-se está precisão, comumente, em termos da diferença numérica entre um dado valor experimental e o valor médio de todos os resultados experimentais. A amplitude de um conjunto de resultados é a diferença numérica entre o resultado mais alto e o mais baixo. Este número é também significante da precisão das medidas. As medidas de precisão mais importantes, no entanto, são o desvio padrão e a variância. A diferença entre o resultado analítico mais provável e o verdadeiro valor associado à amostra representa o erro da análise, fornecendo uma indicação da exatidão da análise. Pode-se melhorar a precisão da medida por repetição com tratamento estatístico adequado dos valores. A titulação é um procedimento que possui um efeito semelhante. Em uma titulação instrumental, tem-se a oportunidade para (e em várias situações deve-se) fazer uma série inteira de medidas, tanto antes como após o ponto final; desenhando uma curva uniforme através desses pontos, obtém-se quase o mesmo efeito na precisão total que se alcançaria tomando o mesmo número de leituras individuais em uma solução, sem titular. (Deve-se lembrar, é claro, que a informação obtida com e sem titulação não pode ser, mesmo idealmente, a mesma, mas se pode referir a diferentes estados de equilíbrio). A precisão conseguida por um método, quando comparada com a obtida por outro, frequentemente é afetada pela forma da curva-resposta, independentemente da capacidade inerente do instrumento de detectar sinais. A maioria dos métodos analíticos discutidos envolve a comparação de uma propriedade física da amostra com a correspondente de um padrão ou de uma série de padrões contendo a mesma substância em quantidade conhecida. Pode-se conseguir isso através de uma curva de calibração, que é um gráfico da grandeza da propriedade física em função da concentração do constituinte desejado (ou alguma função simples da concentração, como seu logaritmo ou recíproco). Em alguns casos, a forma da curva é prevista pela teoria (Lei de Beer, Equação de Ilkovic, etc.) e pode ser mais conveniente fazer um cálculo baseado na equação de Nernst do que usar uma curva de calibração. Esse é o caso, por exemplo, da determinação de um cátion por medida do potencial da meia-cela: a equação de Nernst fornecerá diretamente a informação desejada, mas representa realmente a curva que se pode desenhar (diferença de potencial em função do logaritmo da concentração) para a comparação gráfica das amostras desconhecidas com a solução-padrão, da qual se calculou, originalmente, Eo. Outro procedimento geral para comparação entre amostras e padrões é enquadrar a mostra entre dois padrões convenientemente próximos, um pouco abaixo e um pouco acima, em relação à quantidade medida. Isso encontra aplicação especialmente em tubos de Nessler e em outros comparadores ópticos, onde se iguala diretamente a intensidade das cores com o 
olho humano. Em todas as comparações é altamente desejável que os padrões reproduzam o mais possível as amostras desconhecidas. Esse princípio resulta na redução substancial dos erros sistemáticos, que têm o mesmo efeito em todas as soluções. Em alguns casos, pode-se aumentar muito a precisão, pois se pode aplicar a expansão da escala total do instrumento para medir a diferença entre essas duas grandezas próximas, em vez de se medir a distância de cada grandeza a partir do zero.

Deve-se lembrar que a comparação com padrões não pode melhorar a precisão de uma análise, mas pode ter um efeito na exatidão, que nunca pode ser melhor que a dos padrões. A preparação e preservação de padrões para soluções extremamente diluídas (micromolar a nanomolar) podem ser muito difíceis. As paredes de um recipiente de vidro apresentam uma tendência em adsorver o soluto e podem reduzir a concentração significativamente abaixo do valor pretendido. Em casos favoráveis, pode-se contornar isso pela precaução em enxaguar o recipiente com um pouco da solução que se deve guardar. As extensas séries de amostras-padrão, disponíveis ao custo nominal no National Bureau of Standards, Washington, fornecem uma importante ajuda no sentido da padronização global. Cada amostra é acompanhada de um certificado apresentando a concentração de cada constituinte a partir dos elementos principais até os presentes apenas em alguns milésimos por cento. Por meio dessas amostras, pode-se testar quase todo tipo de análise na área de metais, ligas e minérios quanto à precisão e à exatidão. Adição-padrão é um processo geralmente aplicável para realizar a comparação com um padrão. Foi mencionado na discussão de alguns métodos instrumentais (polarografia, por exemplo), mas se pode adaptar facilmente a outros. Faz-se uma leitura com a amostra a ser analisada, em seguida adiciona-se sob agitação uma quantidade medida do padrão à amostra e repetese a medida. Se a análise for destrutiva (a titulação geralmente o é), o padrão deverá ser adicionado a uma segunda alíquota. Em muitas circunstâncias, esse procedimento servirá para identificar a característica do registro que se refere à substância desejada e ao mesmo tempo dará a informação necessária para uma análise quantitativa. A diluição da amostra por adição do padrão deve ser levada em consideração ou desprezada. Essa técnica apresenta a grande vantagem de o padrão e a amostra serem medidos em condições essencialmente idênticas. Mesmo não se conhecendo exatamente o tipo e a quantidade de outras substâncias presentes, estas podem se considerar idênticas nas duas medidas. O objetivo de uma análise é determinar a qualidade ou a composição de um material; para que os resultados analíticos tenham qualquer validade, ou significado, é essencial adotar procedimentos adequados de amostragem.

A amostragem é o processo de extrair de uma grande quantidade de material uma pequena porção que seja realmente representativa da composição de todo o material. Os métodos de amostragem caem em três grupos principais: (a) Aqueles em que todo o material é examinado; (b) A amostragem arbitrária, numa base ad hoc.; (c) Métodos em que parcelas do material são seleciona das com base em probabilidades estatísticas. O procedimento (a) é normalmente impraticável, pois a maioria dos métodos empregados é destrutiva e, em qualquer caso, a quantidade de material a ser examinado pode ser excessiva. Mesmo no caso que uma amostra de dimensões abordáveis, a análise levaria muito tempo, exigiria grandes quantidades de reagentes e monopolizaria os instrumentos durante longos períodos; A amostragem de acordo com (b) é completamente não-científica e pode levar à tomada de decisões com informações inadequadas. Neste caso, 
como a coleta de amostras é inteiramente arbitrária, é impossível qualquer forma real de controle ou de supervisão analíticos. Em face destas razões, a única base confiável para a amostragem deve ser uma base matemática, com a adoção de probabilidades estatísticas. Isto significa que, embora nem todos os itens ou nem todas as partes da amostra sejam analisados, as limitações da escolha são cuidadosamente calculadas e conhecidas de antemão. Tendo-se calculado o grau de risco aceitável, ou de margem de variação, escolhe-se então um plano de amostragem que dará a informação e o controle máximos compatíveis com a rotatividade das amostras. No caso de amostragem de bateladas, por exemplo, a escolha das amostras individuais se faz de acordo com tabelas randômicas que asseguram a ausência de fatores pessoais na escolha. $O$ procedimento de amostragem pode envolver alguns estágios anteriores à análise do material. Na maioria dos casos, os materiais a granel não são homogêneos, como é o caso de minerais, de sedimentos, de alimentos. Podem conter partículas de composições diferentes que não estão distribuídas uniformemente pela massa do material. Neste caso, retiram-se amostras primárias tomadas de maneira aleatória de pontos do material, de modo que cada amostra tenha a mesma chance que qualquer outra de ser escolhida. A combinação destas amostras primárias forma a amostra bruta. Muitas vezes a amostra bruta é muito grande para uma análise direta e deve ser dividida para proporcionar uma subamostra. A subamostra pode exigir um tratamento, como por exemplo, a redução do tamanho das partículas, ou a completa mistura, antes de se obter a amostra de ensaio ou análise. Esta amostra deve ter a mesma composição que a amostra bruta. Deve-se acentuar, no entanto, que a totalidade do objeto pode constituir a amostra analítica.

Os erros de amostragem, especialmente no caso de sólidos heterogêneos, podem ser a origem mais importante da incerteza da análise que se faz do material. É importante perceber que, se o erro de amostragem for grande, pode ser suficiente um método analítico rápido, com precisão relativamente baixa.

69. Ao planejar um procedimento de amostragem, devem ser levados em conta os seguintes pontos: (a) O número de amostras a serem tomadas; (b) O tamanho de cada amostra; (c) A realização da análise de cada amostra, ou a preparação, para a análise, de uma amostra composta por duas ou mais amostras primárias (amostra composta). Se a composição do material a granel a ser amostrado for desconhecida, é uma boa prática fazer uma investigação preliminar, mediante a coleta de várias amostras, e a determinação do constituinte de interesse. O outro problema importante relativo à amostragem, é o da dimensão da amostra. O tamanho de uma amostra tomada de material heterogêneo é determinado pela variação do tamanho das partículas e pela precisão que se quer nos resultados da análise. A fonte maior de erros de amostragem pode ser a tomada de amostras primárias do material a granel. Pode-se mostrar, pela teoria da amostragem aleatória, que a exatidão da amostra está determinada pelo seu tamanho global. Então, a variância da amostragem é inversamente proporcional à massa da amostra. No entanto, esta afirmação não é correta se o material a granel for constituído por partículas de tamanhos variáveis; então o número de parcelas tomadas influenciará a exatidão da amostragem. Muitos dos problemas que ocorrem durante a amostragem decorrem da natureza física dos materiais estudados. Embora os gases e os líquidos apresentem dificuldades com relação às suas amostragens, os maiores problemas de uma coleta adequada são encontrados com amostras sólidas. Poucos problemas afetam a homogeneidade de misturas gasosas se o 
vaso de armazenamento não estiver sujeito a variações de temperatura ou de pressão. Podem aparecer dificuldades quando não se toma precauções para eliminar, das válvulas, das torneiras e das tubulações, qualquer outro gás, antes da passagem da amostra. Deve-se tomar cuidado para que nenhum componente gasoso reaja com os dispositivos de amostragem e de análise. Na maioria dos casos, a agitação e a mistura são suficientes para assegurar a homogeneidade do líquido, antes da amostragem. Quando existem fases separadas, é necessário determinar os volumes relativos de cada uma a fim de comparar corretamente a composição de uma fase com a de outra. As fases, em qualquer caso, devem ser amostradas individualmente, pois não é possível obter uma amostra representativa dos materiais combinados mesmo depois de vigorosa agitação conjunta das fases separadas. É com os sólidos que aparecem as dificuldades reais em relação à homogeneidade. Mesmo os materiais que superficialmente têm toda a aparência de materiais homogêneos podem ter, na realidade, concentrações localizadas de impurezas e variações de composição. $O$ procedimento adotado para se obter uma amostra tão representativa quanto possível dependerá, em grande parte, do tipo de sólido. Este processo tem grande importância, pois se não for satisfatoriamente realizado pode-se desperdiçar completamente o trabalho e o tempo investidos na execução da análise cuidadosa da amostra. Se o material for mais ou menos homogêneo, a amostragem é relativamente simples. Se, no entanto, o material for fragmentado e heterogêneo, a amostragem deve ser feita com o maior cuidado e o método dependerá da natureza do sólido a granel. O princípio fundamental da amostragem de material a granel, por exemplo, de um carregamento de carvão ou de minério de ferro, é o de escolher, de maneira sistemática, um grande número de amostras primárias, provenientes de diferentes pontos da carga, e depois combiná-las. Esta amostra bruta da massa total é moída mecanicamente e depois amontoada numa pilha cônica. Cada pá cheia com o material deve ser lançada no vértice do cone e o operador deve circundar o cone à medida que amontoa o material: desta forma assegura-se uma distribuição relativamente uniforme. Depois, o cone é achatado e o monte dividido em quartos. Removem-se dois quartos opostos, que são novamente misturados e amontoados num cone menor, que é outra vez achatado e dividido em quartos. Este processo é repetido, com moagem intermediária se for necessária, até que se tenha uma amostra de peso apropriado (por exemplo, 200 a 300g). Se a quantidade de material for da ordem de 2 a $3 \mathrm{~kg}$ ou menos, a homogeneização pode ser feita pelo seguinte método: o material finamente cominuído é espalhado no centro de uma folha grande de oleado, ou material semelhante. Depois, levantam-se sucessivamente cada canto na direção do canto oposto, fazendo com que as partículas se empilhem umas sobre as outras, e as parcelas de baixo troquem de posição com as de cima da massa; assegura-se assim uma mistura perfeita. Depois, a amostra é amontoada no centro da folha, e o monte dividido em quartos, procedendo-se como descrevemos acima. $O$ processo é repetido com os dois quartos escolhidos até que se tenha uma amostra suficientemente pequena. A amostra final para o laboratório, usualmente com peso entre 25 e $200 \mathrm{~g}$, é colocada num frasco hermético. Este método proporciona o que se conhece como 'amostra média' e qualquer análise que dela se faça deve sempre ser comparada com a análise de uma segunda amostra do mesmo material coletado conforme rotina idêntica. Existem também métodos mecânicos para dividir material particulado em amostras de tamanho conveniente. As amostras obtidas por estes meios são usualmente representativas do material a granel 
dentro dos limites de $\pm 1 \%$ e estão conforme as exigências da British Standards Institution. Divisores de amostras existem com capacidades até 10L. Operam mediante uma série de frascos de amostragem que se sucedem rapidamente, mediante movimento giratório, sob a descarga de um funil de carregamento, ou mediante uma cascata rotatória que alimenta, com frações da amostra, uma série de compartimentos separados. Os divisores de amostra podem proporcionar uma grande economia de tempo nos laboratórios que operam com grandes quantidades de material pulverulento ou de minerais. A amostragem de metais e de ligas pode ser feita por meio de buracos broqueados, num lingote representativo, em pontos escolhidos; todo o material dos buracos é coletado e misturado; usa-se uma amostra de tamanho apropriado para a análise. Virolas ou raspas da face externa não são apropriadas, pois possuem frequentemente impurezas superficiais das formas ou dos moldes. Em alguns casos, nos quais a moagem apresenta problemas, é possível obter uma amostra homogênea apropriada pela dissolução de uma parcela do material num solvente apropriado. Antes da análise, a amostra sólida representativa é usualmente secada a 105-110oC, ou a uma temperatura mais alta, se for necessário, até peso constante. Os resultados da análise são então relatados em base 'seca', ou seja, na base de um material seco numa temperatura especificada. A perda de peso na secagem pode ser determinada e os resultados relatados, se assim se quiser, na base 'úmida' original. Estes dados só possuem significado real se o material não for apreciavelmente higroscópico e não ocorram, durante a secagem, alterações químicas além da perda de água. No decorrer da análise quantitativa sistemática, as incógnitas fornecidas para a análise são, usualmente, parcelas de amostras que foram finamente cominuídas até a uniformidade. Deve-se ter consciência de que embora seja possível generalizar os procedimentos de amostragem, todas as indústrias têm seus próprios métodos estabelecidos para a obtenção do registro da quantidade e/ou da qualidade dos seus produtos. Os procedimentos de amostragem de folhas de tabaco serão, como é evidente, diferentes dos que se usam para fardos de algodão ou para cargas de carvão. Embora os tipos e amostras sejam consideravelmente diferentes, os métodos analíticos que se usam, posteriormente, são de aplicação geral. Se o material for duro (por exemplo, uma amostra de rocha), é inicialmente quebrado em pequenos fragmentos sobre uma chapa de aço duro, com um martelo endurecido. Impede-se a perda de fragmentos cobrindo-se a chapa com um anel de aço ou mediante outro dispositivo. Os fragmentos de menor tamanho podem ser quebrados num almofariz de percussão (também conhecido como almofariz Plattner). O almofariz e o pistilo são construídos, inteiramente, em aço de ferramenta, duro. Colocam-se um ou dois pequenos fragmentos no almofariz, insere-se o pistilo na sua posição e golpeia-se ligeiramente com um martelo, até reduzir os pedaços a um pó grosseiro. A substância dura pode ser tratada, na sua totalidade, desta maneira. O pó grosso é então cominuído num gral de ágata, em pequenas quantidades de cada vez. Diz-se que um gral de mulita é superior ao de ágata. A mulita é um material cerâmico homogêneo que é mais duro, mais resistente à abrasão e menos poroso do que a ágata. Há no comércio um gral e pistilo de safira sintética (composto essencialmente por uma fôrma de óxido de alumínio puro, especialmente preparada); é extremamente dura (dureza comparável à do carbeto de tungstênio) e cominuirá materiais que não se reduzem com facilidade em almofarizes de cerâmica ou de metal. Existem também, no comércio, almofarizes mecânicos (acionados a motor). A operação com muitos materiais está cheia de riscos, e estes riscos não 
diminuem na amostragem de materiais destinados à análise química. $\mathrm{O}$ operador da amostragem deve sempre envergar vestimenta protetora adequada e, se for possível, ter conhecimento detalhado prévio do material que será amostrado.

Quando há o risco de toxidez, devem estar disponíveis, e estabelecidos, os antídotos necessários e os procedimentos de tratamento, antes de principiar a amostragem. Em nenhuma circunstância chamas nuas podem arder nas vizinhanças da área de amostragem. Além da natureza tóxica de muitos gases, os riscos adicionais são os de emissão excessiva de gás, em virtude de modificações de pressão, ignição espontânea de gases inflamáveis e vaporização súbita de gases liquefeitos. Com os líquidos, os perigos aparecem com líquidos que se volatilizam com facilidade e com líquidos facilmente inflamáveis. Em todos os casos, as precauções devem ser ainda maiores do que em circunstâncias normais, em face da natureza e das condições imprevisíveis da tomada de amostras. O operador deve estar sempre preparado para o inesperado, o que pode ocorrer, por exemplo, se num vaso houver excesso de pressão, ou se um líquido errado foi posto num frasco de embalagem. Os líquidos tóxicos e desconhecidos jamais devem ser aspirados com a boca, por meio de tubos ou pipetas. Mesmo a amostragem de sólidos não pode ser feita descuidadamente, e o operador deve usar sempre máscara de proteção até que tenha ficado evidente não haver risco com o material pulverulento. Deve-se ter presente que a amostragem de substâncias radioativas é uma operação sempre especializada e que só pode ser efetuada sob condições estritamente controladas e em áreas de acesso restrito. Em quase todas as circunstâncias o operador deve estar protegido contra as emanações radioativas do material que está sendo amostrado. A amostragem correta dos materiais é, portanto, relevante sob dois aspectos principais. Primeiro, para obter-se uma parcela representativa do material para a análise. E segundo, para impedir a ocorrência de acidentes na amostragem de materiais perigosos.

\section{REFERÊNCIAS}

ALMEIDA, J. R.; SILVA, C. E.; SILVA, C. V. V.; AGUIAR, L. A.; GARCIA, V. S.; SOUZA, C. P.; LENZ, E. R. S.; LINS, G. A.; ALMEIDA, S. M.. Multifatorialidade em saúde ambiental. Environmental Scientiae, v.1, n.2, p.26-47, 2019. DOI: http://doi.org/10.6008/CBPC2674-6492.2019.002.0002

ALMEIDA, J. R.; SILVA, C. E.; SILVA, C. V. V.; AGUIAR, L. A.; GARCIA, V. S.; SOUZA, C. P.; LENZ, E. R. S.; LINS, G. A.; ALMEIDA, S. M.. Política e economia de vigilância em saúde ambiental. Environmental Scientiae, v.1, n.2, p.1-25, 2019. DOI: http://doi.org/10.6008/CBPC2674-6492.2019.002.0001
ALMEIDA, J. R.; SILVA, C. E.. Análisis "ex-post-facto" del estado consumatório denotativo de los principios de la Declaración del Rio en padrón personal. Educationis, Aquidabã, v.1, n.1, p.17-21, 2013. DOI: http://dx.doi.org/10.6008/ESS2318-3047.2013.001.0002

SOUZA, F. M. N.; SILVA, C. E.; AGUIAR, L. A.; ALMEIDA, J. R.. Proposta para utilização da simulação computacional em análise de risco, avaliação de desempenho e sistemas de gestão ambiental. Revista Ibero-Americana de Ciências Ambientais, v.2, n.2, p.39-63, 2011. DOI: http://doi.org/10.6008/ESS2179-6858.2011.002.0003

A CBPC - Companhia Brasileira de Produção Científica (CNPJ: 11.221.422/0001-03) detém os direitos materiais desta publicação. Os direitos referem-se à publicação do trabalho em qualquer parte do mundo, incluindo os direitos às renovações, expansões e disseminações da contribuição, bem como outros direitos subsidiários. Todos os trabalhos publicados eletronicamente poderão posteriormente ser publicados em coletâneas impressas sob coordenação da Sustenere Publishing, da Companhia Brasileira de Produção Científica e seus parceiros autorizados. Os (as) autores (as) preservam os direitos autorais, mas não têm permissão para a publicação da contribuição em outro meio, impresso ou digital, em português ou em tradução. 